\title{
Establishment and characterization of a human cholangiocarcinoma cell line
}

\author{
STEPHANIE MA ${ }^{1,2^{*}}$, LIANG HU $^{1 *}$, XIAO-HUI HUANG ${ }^{3}$, LIANG-QI CAO ${ }^{4}$, \\ KWOK WAH CHAN ${ }^{1}$, QIAN WANG ${ }^{4}$ and XIN-YUAN GUAN ${ }^{2}$ \\ ${ }^{1}$ Department of Pathology, The University of Hong Kong, University Pathology Building, 102 Pokfulam Road, Hong Kong; \\ ${ }^{2}$ Department of Clinical Oncology, The University of Hong Kong, Faculty of Medicine Building, Laboratory Block, \\ 10/F, Room 56, 21 Sassoon Road, Hong Kong; Departments of ${ }^{3}$ Hepatobiliary Surgery, and ${ }^{4}$ Surgery, \\ First Affiliated Hospital, Sun Yat-sen University, 72 Second Zhongshan Road, Guangzhou 510080, P.R. China
}

Received February 12, 2007; Accepted June 1, 2007

\begin{abstract}
Cholangiocarcinoma (CC) is a rare malignant tumor arising from the biliary tract. The disease is notoriously difficult to diagnose and is usually fatal due to its late clinical presentation and the lack of effective non-surgical therapeutic strategies. To date, little is known about the cancer biology of the disease and the establishment and characterization of only a few CC cell lines have been reported. We report here the establishment of a new human cancer cell line, HKGZ$\mathrm{CC}$, from a moderate to poorly differentiated intrahepatic bile duct carcinoma from a Chinese patient. Morphological characteristics, growth kinetics, ability to grow on anchorageindependent soft agar, tumorigenicity in nude mice and cytogenetic features of the cell line were investigated. Chromosome banding karyotype and comparative genomic hybridization analyses revealed chromosomal changes in 1pter-p31, 1q31qter, 3q, 8q21-qter, 9pter-9q34, 10, 13q21-qter and X. This newly established cell line should serve as a useful model for studying the molecular pathogenesis of CC.
\end{abstract}

\section{Introduction}

Cholangiocarcinoma (CC), tumor of the biliary epithelium, accounts for $3 \%$ of all gastrointestinal cancers and is the second most common primary hepatic tumor (1). The incidence of and mortality rate for the disease varies considerably in different geographic regions, with the incidence highest in Thailand, P.R. China and other parts of Southeast Asia. Yet for reasons

Correspondence to: Dr Xin-Yuan Guan, Department of Clinical Oncology, The University of Hong Kong, Faculty of Medicine Building, Laboratory Block, 10/F, Room 56, 21 Sassoon Road, Hong Kong, P.R. China

E-mail: xyguan@hkucc.hku.hk

${ }^{*}$ Contributed equally

Key words: cholangiocarcinoma, cell line, HKGZ-CC, liver cancer that are not clear, rising incidence rates, paralled by mortality rates, have also been documented globally (1-3). The prognosis of patients with CC is dismal as the disease is notoriously difficult to diagnose and is usually fatal due to its late clinical presentation and the lack of effective non-surgical therapeutic modalities. Most patients have unresectable disease at presentation and die within 12 months following diagnosis. Overall survival rate is poor, with less than $5 \%$ of patients surviving to 5 years (1). Established risk factors, including conditions associated with chronic biliary tract inflammation account for a small proportion of cases; and additional risk factors such as cirrhosis, infection with hepatitis $B$ virus and hepatitis $C$ virus are now also being recognized to contribute to the development of the disease $(1,2)$. Yet despite our growing understanding of the disease, the precise molecular and genetic steps for the oncogenesis of CC remain largely unknown. This underlines the need for a better understanding of the molecular pathogenesis of the disease. For this purpose, a permanently growing, well-characterized cell line can be the most indispensable tool. Although a number of biliary tract cancer cell lines have been reported in the literature to date, most of these cell lines either lack detailed characterization or are mostly established from the more common extrahepatic CC (4-15). Of the cell lines established from intrahepatic CC (16-22), all are either of Japanese, Korean or Thai origin (Table I). Despite the prevalence of CC in P.R. China, no cell lines have been established from a Chinese patient to date. We report here the establishment and characterization of a new human intrahepatic CC cell line, named HKGZ-CC from a Chinese patient. This newly established cell line would provide a useful in vitro model for the study of the pathogenesis of CC.

\section{Materials and methods}

Specimen collection. The specimen was obtained from a 76-year-old Chinese man who underwent surgical resection at the First Affiliated Hospital of Sun Yat-sen University (Guangzhou, P.R. China) for intrahepatic CC in the right lobe of the liver. The size of the specimen was $6 \times 5 \times 3 \mathrm{~cm}$. No portal vein, lymph node or distant metastasis was detected at the time of surgical resection. Laboratory investigations at admission 
Table I. Documented human cholangiocarcinoma cell lines.

\begin{tabular}{|c|c|c|c|c|c|c|}
\hline Cell line & Age (years) & Sex & Site & Race & Differentiation & Ref. \\
\hline KKU-100 & 65 & $\mathrm{~F}$ & Porta hepatis & Thai & Poor & 4 \\
\hline TGBC-47 & - & - & Extrahepatic & Japanese & Poor & 12 \\
\hline TGBC-51 & - & - & Papilla of vater & Japanese & & \\
\hline TBCN6 & - & - & Extrahepatic & Japanese & Poor & \\
\hline SNU-245 & - & - & Extrahepatic & Korean & Well & 5 \\
\hline SNU-308 & - & - & Gall bladder & Korean & Moderate & \\
\hline SNU-478 & - & - & Ampulla of vater & Korean & Poor & \\
\hline SNU-869 & - & - & Ampulla of vater & Korean & Well & \\
\hline SNU-1079 & - & - & Intrahepatic & Korean & Moderate & \\
\hline SNU-1196 & - & - & Extrahepatic & Korean & Moderate & \\
\hline SCK & 57 & M & Intrahepatic & Korean & Moderate & 16 \\
\hline JCK & 59 & $\mathrm{M}$ & Intrahepatic & Korean & Moderate & \\
\hline Cho-CK & 72 & M & Intrahepatic & Korean & Moderate & \\
\hline Choi-CK & 57 & M & Intrahepatic & Korean & Poor & \\
\hline HBDC & 75 & $\mathrm{~F}$ & Extrahepatic & Japanese & Poor & 7 \\
\hline ICBD-1 & 71 & M & Extrahepatic & Japanese & Poor & 13 \\
\hline OCUCh-LM1 & 61 & M & Extrahepatic & Japanese & Well & 8 \\
\hline TFK-1 & 63 & M & Extrahepatic & Japanese & - & 9 \\
\hline $\mathrm{KMBC}$ & 73 & M & Extrahepatic & Japanese & Moderate to poor & 14 \\
\hline KMC-1 & 62 & M & Intrahepatic & Japanese & - & 22 \\
\hline CC-SW-1 & - & - & Intrahepatic & - & Moderate & 21 \\
\hline CC-LP-1 & - & - & Intrahepatic & - & Moderate & \\
\hline HuCCA-1 & - & - & Intrahepatic & Thai & - & 17 \\
\hline MEC & - & - & Extrahepatic & Japanese & Moderate & 10 \\
\hline PCI:SG231 & - & - & Intrahepatic & - & - & 20 \\
\hline HuCC-T1 & 56 & - & Intrahepatic & Japanese & Moderate & 19 \\
\hline CHGS & - & - & - & Japanese & - & 6 \\
\hline НuH-28 & - & - & Extrahepatic & Japanese & - & 11 \\
\hline HChol-Y1 & - & - & Intrahepatic & Japanese & - & 18 \\
\hline Mz-ChA-1 & - & - & Gall bladder & - & - & 15 \\
\hline Mz-ChA-2 & - & - & Gall bladder & - & - & \\
\hline SK-ChA-1 & - & - & Extrahepatic & - & - & \\
\hline
\end{tabular}

Bold, intrahepatic bile duct carcinoma.

showed normal levels of $\alpha$-fetoprotein (AFP) $(4.63 \mu \mathrm{g} / \mathrm{l}$, normal 0-20 $\mu \mathrm{g} / \mathrm{l})$ but elevated levels of CA125 (85.03 U/l, normal 0-35 U/1), CA19-9 (4402.07 U/1, normal 0-35 U/1) and carcinoembryonic antigen (CEA) $(34.7 \mu \mathrm{g} / 1$, normal 0-5 $\mu \mathrm{g} / \mathrm{l})$. Serologic hepatitis B virus (HBV) examination of this patient was negative. The tumor was histopathologically classified as moderate to poorly differentiated intrahepatic bile duct carcinoma.
Primary culture and establishment of cell line. Tumor specimens were washed in complete DMEM supplemented with $10 \%$ FBS, penicillin $(100 \mathrm{U} / \mathrm{ml})$ and streptomycin $(100 \mu \mathrm{g} / \mathrm{ml})$. After rinsing in the same medium twice, tumor tissues were minced into $1-\mathrm{mm}^{3}$ pieces and incubated with $1 \mathrm{X}$ Accumax (1200-2000 U/ml proteolytic activity containing collagenase and DNase; Innovative Cell Technologies, Inc., San Diego, CA, USA) at $10 \mathrm{ml} / \mathrm{g}$ tissue in DPBS (Invitrogen, 
Carlsbad, CA, USA) for $20 \mathrm{~min}$ at $37^{\circ} \mathrm{C}$ under constant rotating conditions. Single cell suspension was obtained by filtering the supernatant through a $100-\mu \mathrm{m}$ and $40-\mu \mathrm{m}$ cell strainer (BD Biosciences, San Jose, CA). The resulting filtrate was topped up with an equal volume of complete DMEM and centrifuged at $1000 \mathrm{rpm}$ at $4^{\circ} \mathrm{C}$ for $5 \mathrm{~min}$. The pellet was resuspended in complete DMEM and seeded onto plastic flasks. Cultures were incubated at $37^{\circ} \mathrm{C}$ in a humidified atmosphere of $95 \%$ air and $5 \% \mathrm{CO}_{2}$. Medium was changed twice a week. Cells were subcultured when they reached $70-80 \%$ confluence.

During the subsequent period of continuous propagation by subculture, the cells were sampled at intervals, put in freezing medium containing 40\% DMEM, 50\% FBS and $10 \%$ DMSO, and stored in liquid nitrogen. After thawing, stored cells could be propagated in culture without noticeable change in growth and morphology. The cell line was designated HKGZ-CC (Hong Kong Guangzhou - Cholangiocarcinoma).

Morphologic examination and growth kinetics. Unstained cultured cells were routinely monitored and photographed with a phase-contrast microscope.

Cells of passage 15 were studied to estimate the populationdoubling time. A suspension of $2 \times 10^{5}$ cells was plated in $25-\mathrm{cm}^{2}$ culture flasks. Cells were detached from the flasks with trypsin and the average number of viable cells from two culture flasks was counted every $24 \mathrm{~h}$ in a hemacytometer chamber in the presence of trypan-blue dye. Cells were counted for up to 17 days. The growth curve was plotted and the doubling time of the cell population was estimated during the logarithmic growth phase.

Anchorage-independent growth assay in soft agar. Anchorageindependent growth was assessed by colony-formation ability in soft agar. Cells were suspended in soft agar and growth medium in 6-well plates at a density of 5000 cells per well. After 2-3 weeks, colonies ( $\geq 10$ cells) were counted under the microscope in ten fields per well and photographed. Data represent results from at least two independent experiments performed in triplicate.

Tumorigenicity in nude mice. The study protocol was approved by and performed in accordance with the Committee of the Use of Live Animals in Teaching and Research at the University of Hong Kong. Cells of passage 8 were prepared to determine their tumorigenicity in nude mice. Cultured cells $\left(2 \times 10^{6}\right)$ were harvested, washed, resuspended in $0.1 \mathrm{ml}$ of complete DMEM, and injected subcutaneously into the right flanks of two 4- to 5-week-old male nude mice. Animals were examined every week for the development of tumors. Tumor-bearing mice were sacrificed. Tumor tissue was excised, fixed in $10 \%$ formalin, and processed for routine histopathologic examination.

Cytogenetic analysis. Chromosome harvest was performed after short-term culture. Metaphase chromosomes were stained by standard trypsin-G banding method. Twenty-five metaphases were characterized. The description of karyotypic abnormalities followed the recommendations of the International System for Human Cytogenetic Nomenclature (23). Structural and numeric abnormalities were identified as clonal changes when found in $\geq 10$ cells.
Comparative genomic hybridization (CGH). Genomic DNA was extracted from the tumor sample with proteinase K/ sodium dodecyl sulfate digestion and phenol/chloroform/ isoamyl alcohol extraction. Normal reference DNA was prepared from peripheral blood lymphocytes of healthy donors. Metaphases were prepared following standard procedures from peripheral blood lymphocytes of a healthy male donor. CGH was performed as described previously (24). Briefly, $1 \mu \mathrm{g}$ of genomic DNA from the tumor sample and sex-matched normal reference was labeled directly with SpectrumGreen-dUTP and SpectrumRed-dUTP (Vysis, Downers Grove, IL, USA) by nick translation, respectively. Labeled tumor DNA (500 ng) and normal DNA probes were denatured and hybridized to normal metaphase chromosomes at $37^{\circ} \mathrm{C}$ in a moist chamber for $48 \mathrm{~h}$. The slide was then washed in $0.4 \mathrm{X} \mathrm{SSC} / 0.3 \% \mathrm{NP}-40$ at $75^{\circ} \mathrm{C}$ for $2 \mathrm{~min}$ and then in $2 \mathrm{X} \mathrm{SSC} / 0.1 \% \mathrm{NP}-40$ at room temperature for $2 \mathrm{~min}$. Slides were briefly counterstained with $1 \mu \mathrm{g} / \mathrm{ml}$ DAPI in an antifade solution.

Digital image analysis. Hybridized metaphase chromosomes were analyzed using a digital image analysis system containing a Zeiss Axiophot microscope equipped with a Metachrome II cooled-charged device camera (Zeiss, Oberkochen, Germany). Three images of each metaphase were captured using filter wheel-mounted, single band excitation Rhodamine, FITC, and DAPI filters. The image analyses were carried out using Quips CGH program (Vysis). Ten metaphases were analyzed to generate fluorescent ratio profiles in each case. Interpretation of the profiles was performed according to the program guidelines. The threshold used for the interpretation of gains and losses of a DNA sequence copy number was defined as a tumor/ reference ratio $>1.2$ or $<0.8$, respectively, with both the standard and the reverse hybridization methods. High-copy-number amplification was defined as a tumor/reference ratio $>1.50$.

\section{Results}

Morphology and culture characteristics. The HKGZ-CC epithelial cells grew gradually from explants of a CC specimen and formed sparse colonies within 26 days of primary culture. The first successful subculture was performed at approximately one and a half months and the second one 7 days later. Once cell growth started, it tended to proceed progressively without periods of acute cell death. The contaminating fibroblasts gradually decreased and finally disappeared. The cells began to grow quickly at the 6th passage and were passaged for more than 40 generations thereafter.

The cultured HKGZ-CC cells grew as an adherent monolayer with characteristic epithelial morphologic features (Fig. 1A and B). The cells maintained consistent morphology from the primary culture to the following passages. After thawing, the cryopreserved cells could be propagated in culture without noticeable change in growth and morphology. The growth curve of HKGZ-CC cells is shown in Fig. 1C. The population doubling time of HKGZ-CC was approximately $48 \mathrm{~h}$. HKGZ-CC cells were able to produce recognizable colonies in soft agar (data not shown).

Tumorigenicity in nude mice. The HKGZ-CC cells were highly tumorigenic in athymic nude mice. Within 21 days after 

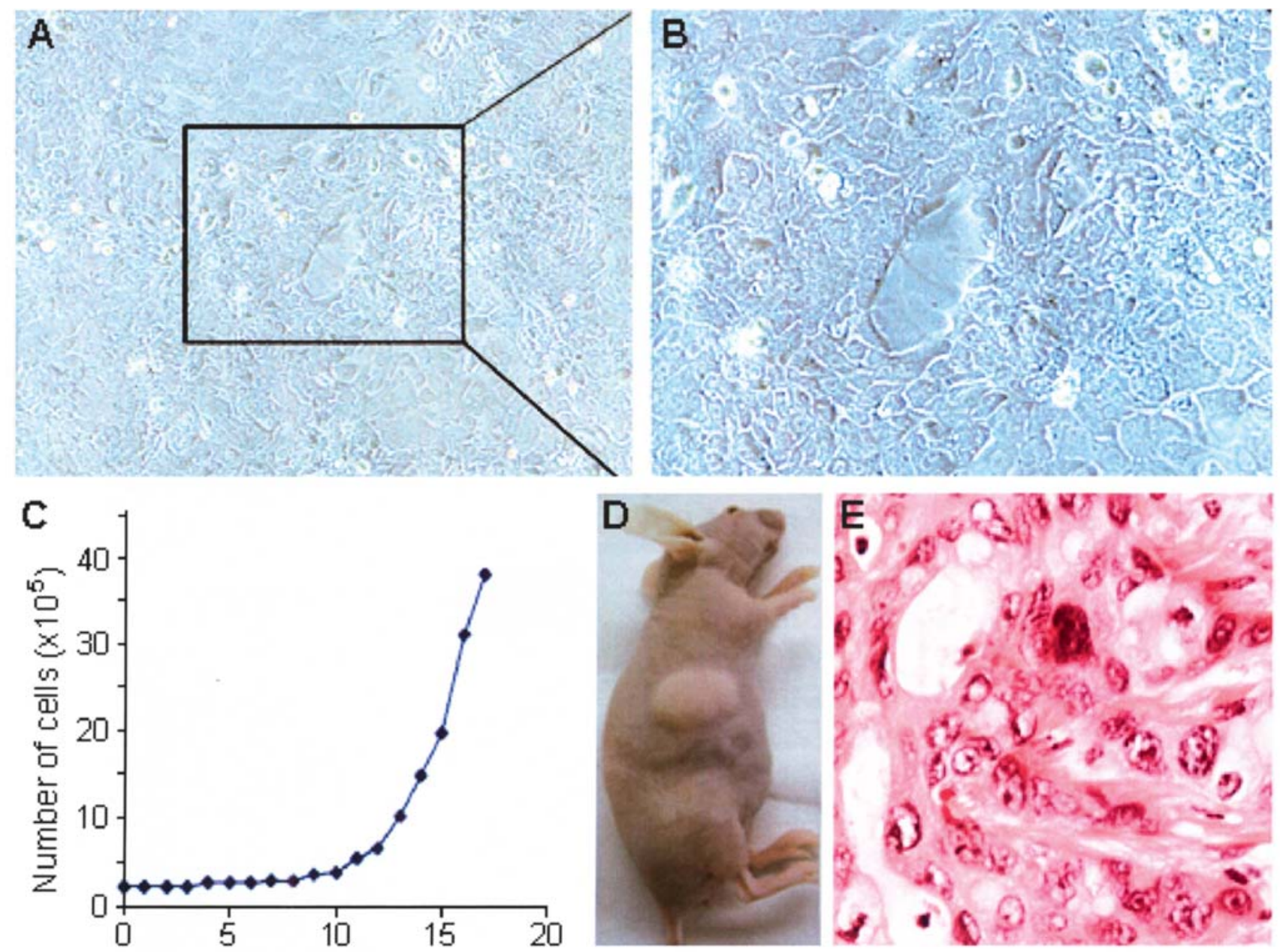

Figure 1. (A and B) HKGZ-CC cells in tissue culture. The cells grew in monolayer sheets and exhibited typical malignant epithelia in morphology. Micrographs of cultured HKGZ-CC cells at phase contrast x100 (A) and x200 (B). (C) Growth curve of HKGZ-CC cells. (D) Tumorigenicity test of HKGZ$\mathrm{CC}$ cells in nude mice showing a tumor mass 3 weeks following subcutaneous injection of $2 \times 10^{6}$ HKGZ-CC cells. (E) Histology of xenografted tumor of HKGZ-CC cells shows a moderate to poorly differentiated CC (H\&E x400 magnification).

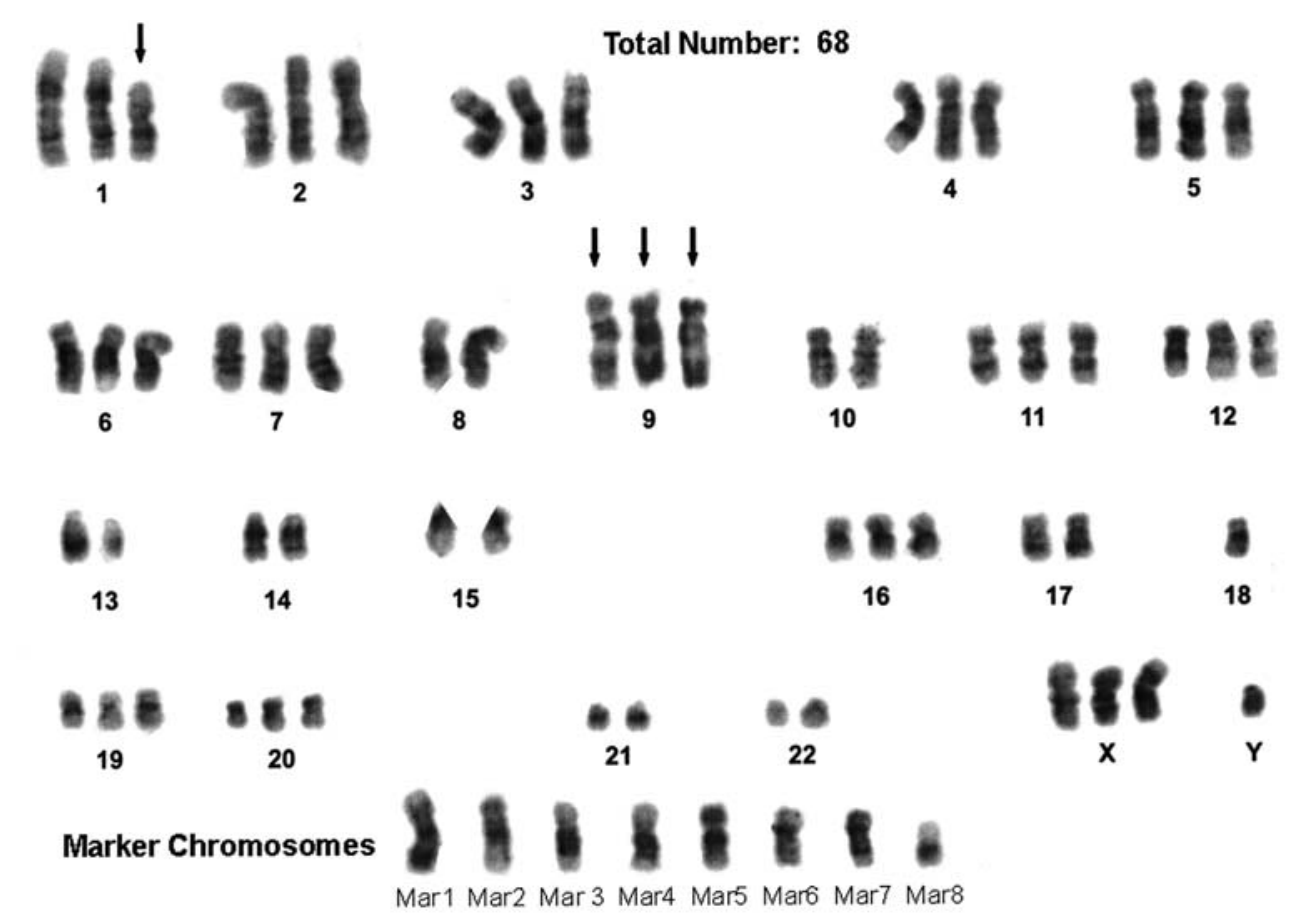



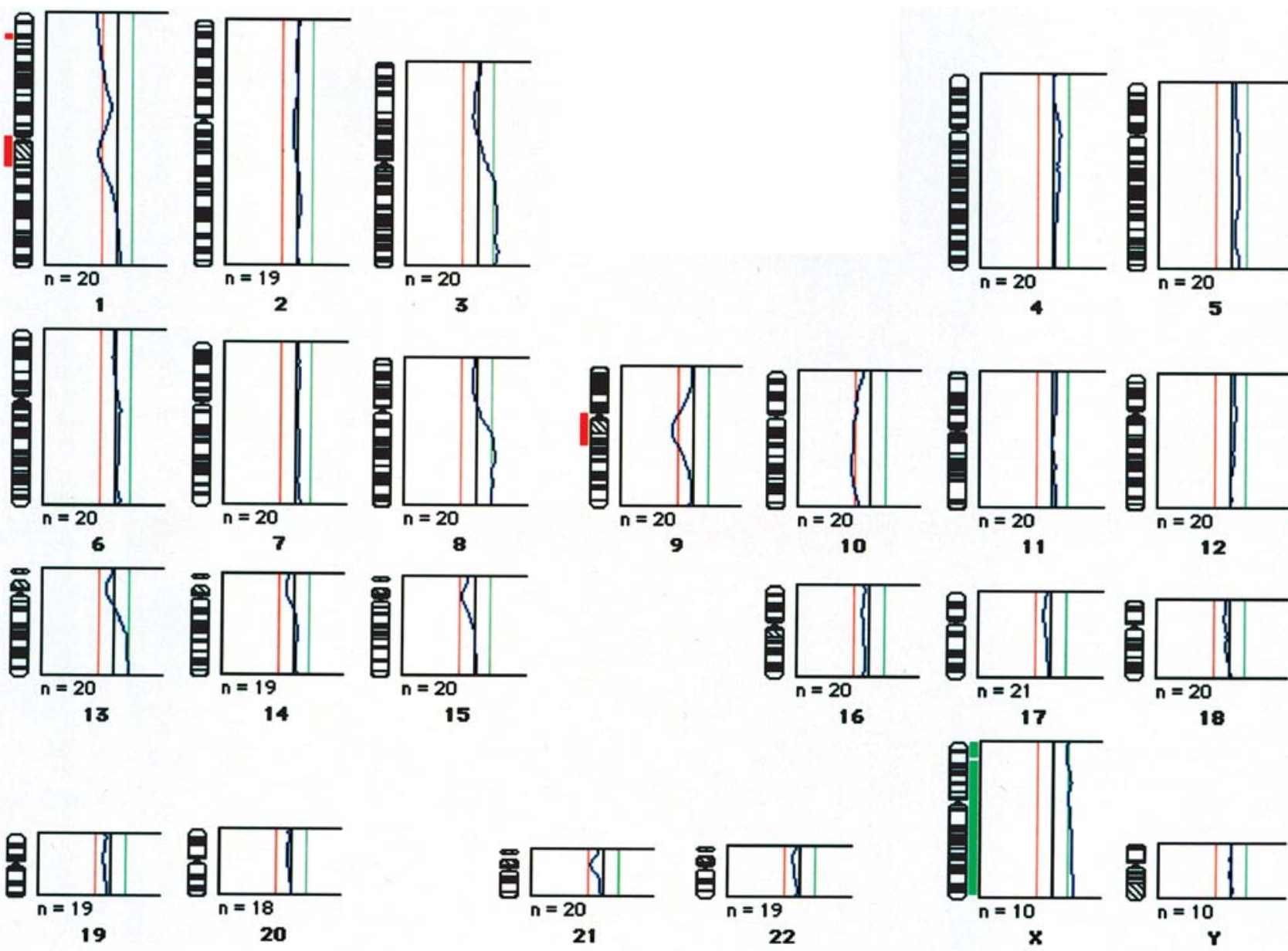

18

Figure 3. Comparative genomic hybridization analysis of chromosomal alterations in HKGZ-CC cells. Ratio profiles are shown to the right of chromosome ideograms. The baseline (middle) ratio is 1.0 . The left-sided shift indicates a ratio of 0.8 and the right-sided shift indicates a ratio of 1.2 . The ratio profile was calculated as a mean of ten chromosomes. The solid bars to the left and right of chromosome ideograms indicate loss and gain of DNA sequence, respectively.

subcutaneous injection of cells, visible tumors developed in all of the 2 nude mice at the site of inoculation (Fig. 1D). Histological examination of the xenotransplanted nodules showed moderate to poorly differentiated CC, similar to the description of the original resected tumor of the bile duct from which the HKGZ-CC cell line was derived (Fig. 1E).

Cytogenetic analysis. GTG banding analysis found that the HKGZ-CC cell line is a triploid. A representative karyotype is shown in Fig. 2 and the composite karyotype is summarized as follows: $64 \sim 74, \mathrm{XXXY},-1,-1,-8,-10,-13,-14,-15,-17,-18$, $18,-21,-22,+\operatorname{der}(? ; 1)\left(?:: 1 \mathrm{q} 31 \_1 \mathrm{qter}\right),+\operatorname{der}(9 ; ?)(9 \mathrm{pter}+9 \mathrm{q} 34:: ?)$, $+\operatorname{der}(9 ; ?)(9$ pter_9q34::?),+der(9;?)(9pter_9q34::?),+3 9mar.

CGH analysis. Changes in the genomic copy number in HKGZ-CC cells were identified by $\mathrm{CGH}$ analysis. The profile of chromosome copy number change detected by $\mathrm{CGH}$ is shown in Fig. 3. Gains of 3q, 8q21-qter, 13q21-qter and X; and losses of 1pter-p31 and 10 were detected.

\section{Discussion}

Advances in cell culture methods have made it possible to establish a variety of human carcinoma cell lines from surgical and autopsy tissues. Since pure cells in cultures can be used for a vast array of studies that cannot normally be carried out using tissue specimens, the study of permanent cell lines established from human cancers has played a pivotal role in our study and understanding of cancer cell biology .

Only a few long-term intrahepatic CC cell lines have been reported to date. Although the incidence of the disease is prevalent in P.R. China, no cell lines have been established from a Chinese patient thus far.

In this study, we report the establishment and characterization of a new CC cell line, HKGZ-CC, derived from a moderate to poorly differentiated intrahepatic bile duct carcinoma from a Chinese patient. The HKGZ-CC cells grew as an adherent monolayer with characteristic epithelial morphology, with a population doubling time of approximately $48 \mathrm{~h}$. Cultured cells maintained consistent morphology from the primary culture to the following subculture passages. The HKGZ-CC cells had been grown continuously for approximately 5 months, undergoing $>40$ passages; and growth continued even after recovery from cryopreservation. The HKGZ-CC cells also exhibited an ability to form colonies in soft agar. Further, heterotransplantation of the HKGZ-CC cells into nude mice resulted in tumor growth and histological features of the tumor resembled those of the original primary tumor that the cell line was established from. Cytogenetic analysis confirmed that HKGZ-CC cells were of human origin. 
Chromosome aberrations are involved in the malignant transformation and progression of nearly all tumors. Chromosome banding karyotype and $\mathrm{CGH}$ analyses allow for the characterization of and global overview of chromosomal alterations involved in the entire genome of a tumor. To date, only a limited number of studies have investigated the cytogenetic changes in $\mathrm{CC}$ and our understanding of the molecular carcinogenesis of the disease remains limited. Previous investigations of CC-derived cell lines showed chromosomal gains in 2q, 5p, 7p, 8q, 13q, 17q, 18q, 19q and $X$ and chromosomal losses in 1p, 4q, 5q 8p, 9p, 17p, 18q, $19 p, X$ and Y (16,18,25-27). These results are relatively well matched with our findings where gains in chromosomes $8 \mathrm{q}$, $13 \mathrm{q}, \mathrm{X}$ and losses in $1 \mathrm{p}$ were also detected. Yet it is also interesting to note that the newly established cell line only displayed few chromosomal alterations, when compared to other cell lines that have been characterized previously. Our findings suggest that the chromosomal abnormalities detected in this newly established cell line might play a crucial role in the early steps of carcinogenesis of CC.

In this study, we report the establishment and characterization of a new human cholangiocarcinoma cell line derived from a Chinese patient, termed HKGZ-CC. Further study on the various aspects including tumor biology, cellular and molecular carcinogenesis, biomarkers for early diagnosis and drug responses to new therapeutic agents, is needed for a better understanding of $\mathrm{CC}$. The new cell line should provide us with a new experimental model for the research of this disease in the future.

\section{Acknowledgments}

This study was supported in part by a Research Council Grant HKU 7393/04M (Hong Kong).

\section{References}

1. Khan SA, Thomas HC, Davidson BR and Taylor-Robinson SD: Cholangiocarcinoma. Lancet 366: 1303-1314, 2005.

2. Patel T: Cholangiocarcinoma. Nat Clin Pract Gastroenterol Hepatol 3: 33-42, 2006.

3. Olnes MJ and Erlich R: A review and update on cholangiocarcinoma. Oncology 66: 167-179, 2004.

4. Sripa B, Leungwattanawanit S, Nitta T, et al: Establishment and characterization of an opisthorchiasis-associated cholangiocarcinoma cell line (KKU-100). World J Gastroenterol 11: 3392-3397, 2005.

5. Ku JL, Yoon KA, Kim IJ, et al: Establishment and characterization of six human biliary tract cancer cell lines. Br J Cancer 87: 187-193, 2002.

6. Katoh H, Shinbo T, Otagiri $\mathrm{H}$, et al: Character of a human cholangiocarcinoma CHGS, serially transplanted to nude mice. Hum Cell 1: 101-105, 1988.

7. Jiao W, Yakushiji H, Kitajima Y, Ogawa A and Miyazaki K: Establishment and characterization of human hilar bile duct carcinoma cell line and cell strain. J Hepatobiliary Pancreat Surg 7: 417-425, 2000.
8. Yamada H, Chung YS, Arimoto Y, Sawada T, Seki S and Sowa M: Establishment of a new human extrahepatic bile duct carcinoma cell line (OCUCh-LM1) and experimental liver metastatic model. Br J Cancer 71: 543-548, 1995.

9. Saijyo S, Kudo T, Suzuki M, et al: Establishment of a new extrahepatic bile duct carcinoma cell line, TFK-1. Tohoku J Exp Med 177: 61-71, 1995.

10. Yoshida K, Tomizawa H, Ota T, et al: Establishment and characterization of human cholangiocarcinoma, MEC, producing carbohydrate antigen 19-9. Hum Cell 3: 346-351, 1990.

11. Kusaka Y, Tokiwa T and Sato J: Establishment and characterization of a cell line from a human cholangiocellular carcinoma. Res Exp Med 188: 367-375, 1988.

12. Ghosh M, Koike N, Tsunoda S, et al: Characterization and genetic analysis in the newly established human bile duct cancer cell lines. Int J Oncol 26: 449-456, 2005.

13. Takiyama I, Terashima M, Ikeda K, et al: Establishment and characterization of a new human extrahepatic bile duct carcinoma cell line (ICBD-1). Oncol Rep 5: 463-467, 1998.

14. Yano H, Maruiwa M, Iemura A, Mizoguchi A and Kojiro M: Establishment and characterization of a new human extrahepatic bile duct carcinoma cell line (KMBC). Cancer 69: 1664-1673, 1992.

15. Knuth A, Gabbert H, Dippold W, et al: Biliary adenocarcinoma. Characterization of three new human tumor cell lines. J Hepatol 1: 579-596, 1985.

16. Kim DG, Park SY, You KR, et al: Establishment and characterization of chromosomal aberrations in human cholangiocarcinoma cell lines by cross-species color banding. Genes Chromosomes Cancer 30: 48-56, 2001.

17. Sirisinha S, Tengchaisri T, Boonpucknavig S, Prempracha N, Ratanarapee S and Pausawasdi A: Establishment and characterization of a cholangiocarcinoma cell line from a Thai patient with intrahepatic bile duct cancer. Asian Pac J Allergy Immunol 9: 153-157, 1991

18. Yamaguchi N, Morioka H, Ohkura H, Hirohashi $\mathrm{S}$ and Kawai K: Establishment and characterization of the human cholangiocarcinoma cell line HChol-Y1 in a serum-free, chemically defined medium. J Natl Cancer Inst 75: 29-35, 1985.

19. Miyagiwa M, Ichida T, Tokiwa T, Sato J and Sasaki H: A new human cholangiocellular carcinoma cell line (HuCC-T1) producing carbohydrate antigen 19/9 in serum-free medium. In Vitro Cell Dev Biol 25: 503-510, 1989.

20. Storto PD, Saidman SL, Demetris AJ, Letessier E, Whiteside TL and Gollin SM: Chromosomal breakpoints in cholangiocarcinoma cell lines. Genes Chromosomes Cancer 2: 300-310, 1990.

21. Shimizu Y, Demetris AJ, Gollin SM, et al: Two new human cholangiocarcinoma cell lines and their cytogenetics and responses to growth factors, hormones, cytokines or immunologic effector cells. Int J Cancer 52: 252-260, 1992.

22. Iemura A, Maruiwa M, Yano H and Kojiro M: A new human cholangiocellular carcinoma cell line (KMC-1). J Hepatol 15: 288-298, 1992.

23. ISCN: Guidelines for cancer cytogenetics, supplement to an international system for human cytogenetic nomenclature. Mitelman F (ed). S. Karger, Basel, 1991.

24. Guan XY, Fang Y, Sham JST, et al: Recurrent chromosome alterations in hepatocellular carcinoma detected by comparative genomic hybridization. Genes Chromosomes Cancer 29: 110-116, 2000 .

25. Koo SH, Ihm CH, Kwon KC, Park JW, Kim JM and Kong G: Genetic alterations in hepatocellular carcinoma and intrahepatic cholangiocarcinoma. Cancer Genet Cytogenet 130: 22-28, 2001

26. Limpaiboon T, Tapdara S, Jearanaikoon P, Sripa B and Bhudhisawasdi V: Prognostic significance of microsatellite alterations at 1p36 in cholangiocarcinoma. World J Gastroenterol 12: 4377-4382, 2006

27. Uhm KO, Park YN, Lee JY, Yoon DS and Park SH: Chromosomal imbalances in Korean intrahepatic cholangiocarcinoma by comparative genomic hybridization. Cancer Genet Cytogenet 157: 27-41, 2005 . 